\title{
OBJECT DATA REUSE AND INTEGRATION IN ERP
}

\author{
Ming Wang, California State University, ming.wang@calstatela.edu \\ Xuesong Zhang Southeast Missouri State University xzhang@semo.edu \\ Drew Hwang, California State Polytechnic University, Pomona, hwang@csupomona.edu
}

\begin{abstract}
Despite the undeniable object reuse and integration features of Enterprise Resource Planning (ERP), very little research has been published to address its importance in business processes integration. This paper presents a case study to investigate object reuse and integration in ERP systems in the real world scenario. ERP SAP is utilized as an ERP software tool for illustration of the case. The purpose of the paper is to provide guidelines for ERP researchers, practitioners and academia to better understand object reuse and integration in ERP systems.
\end{abstract}

Keywords: ERP, Enterprise Resource Planning, Data Warehouse

\section{INTRODUCTION}

(Enterprise Resource Planning) ERP systems are generic and packaged software systems that provide comprehensive functionality and business process integration across the enterprise. ERP systems, by their multidimensional integrative nature, offer the depth of functionality and breadth of integration to demonstrate how global operations of organizations are managed. ERP software is in place in a majority of large organizations and increasing in use in small and medium-sized organizations. Wide spread of ERP technology has made an organization shift its focus from applications development to enterprise software implementation and configuration rapidly. ERP is a platform that integrates all business functions with its centralized data repository shared by all the business processes in the integrated enterprise-wide system. Unlike other computer applications, ERP has the multidisciplinary scope of enterprise system concepts that requires internal cross-disciplinary coordination [1].

In the nature, an ERP system is a set of large and complex database and data warehouse applications that provide the data necessary for the enterprise business processes. All ERP systems are heavily dependent on centralized data repository. Understanding object data reuse and integration is extremely important for ERP practitioners to acquire and understand across functional business processes while implementing and configuring the ERP software [2, 3, and 5].

The paper reveals object data reuse and integration in business process procedures, application modules, major business processes and business suites of SAP NetWeaver, discusses on ERP data conversion in data warehouses for business intelligence and finally presents data modeling using Global Bike case study provided by SAP University Alliances as a real world scenario. SAP is utilized as an ERP software tool for illustration in the paper.

\section{OBJECT REUSE AND INTEGRATION IN ERP INFRASTRUCTURE}

The ERP SAP object data are standard no matter where the ERP SAP System is being implemented. This section illustrates ERP infrastructure and components. SAP infrastructure consists of predefined object data, business process procedures, application modules, business processes and business suites in NetWeaver. Object data are the smallest units in SAP [7]. Business process procedures (BPPs) are composed of object data. Application modules are composed of a comprehensive set of BPPs. Business processes are composed of related application modules. Business Suites are composed of business processes.

\section{Application Modules}

Twelve application modules are organized into the four categories in SAP as shown in Figure 1. 
Volume XII, No. 1, pp. 392-400, 2011

- The financial management application modules include Financial Accounting (FI), Controlling (CO), Fixed Asset Management (AM) and Project System (PS).

- $\quad$ The logistic modules include Sales \& Distribution (SD), Material Management (MM), Production Planning (PP), Quality Management (QM) and Plant Maintenance (PM).

- The Human Resources (HR) module supports human capital management (HCM), payroll and the planning and control of personnel activities.

- The Common Systems modules include Workflow (WF) and Industry Solutions (IS). WF integrates the functionality of these application modules. IS provides industry-specific solutions to specific organizations.

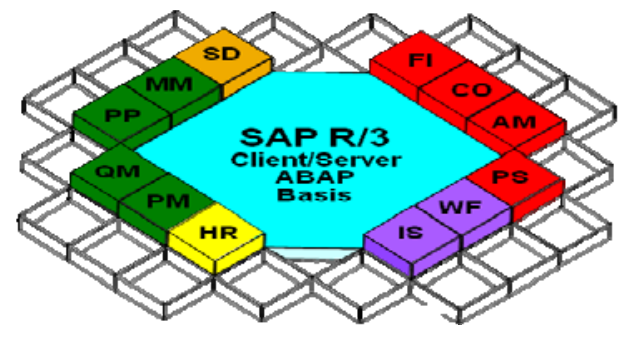

Figure 1 Application modules in SAP [4]

\section{Business process procedures (BPPs)}

Each application module in SAP is a collection of a number of related business process procedures (BPPs), as illustrated in Figure 2. BPPs are the smallest program units that provide the functionality of the SAP System. Many of these BPPs are reused by more than one of the application modules. Business processes and business functionality found in the organization are built with these application modules upon BPPs.

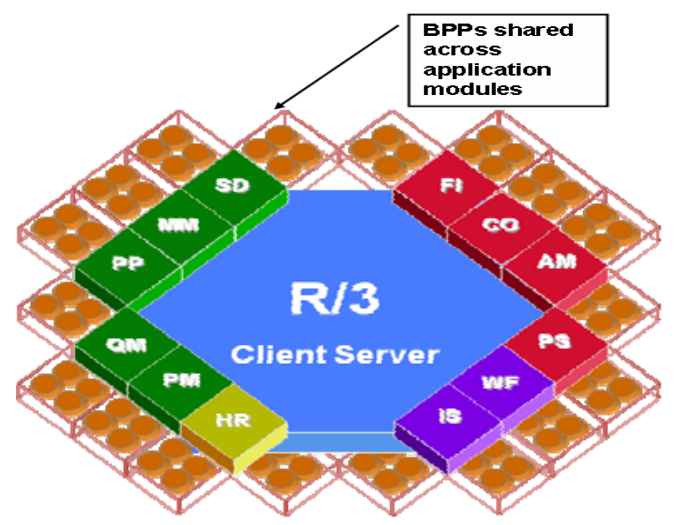

Figure 2 BPPs shared in application modules [4]

\section{Business Processes}

SAP Enterprise software integrates the core business processes found in an organization. Each business process consists of a set of business application modules. The following business processes can be used to illustrate the arrangements of the supply chain management processes. Figure 3 illustrates how application modules are utilized in the business processes. FI and $\mathrm{CO}$ application modules occur in all the following four major business processes. 
Volume XII, No. 1, pp. 392-400, 2011

- Manufacturing planning and execution.

- Procurement

- Financial/management accounting

- Customer Sales Order Management

\begin{tabular}{|c|c|c|c|c|}
\hline $\begin{array}{l}\text { R/3 Business } \\
\begin{array}{l}\text { Application } \\
\text { Module }\end{array}\end{array}$ & Manufacturing & $\begin{array}{c}\text { Customer } \\
\text { Order } \\
\text { Management }\end{array}$ & Procurement & $\begin{array}{c}\text { Financial } \\
\text { Management }\end{array}$ \\
\hline Sales \& Distribution (SD) & $\mathbf{X}$ & $\mathbf{X}$ & & \\
\hline Materials Mgmt. (MM) & $\mathbf{X}$ & $\mathbf{X}$ & $X$ & \\
\hline Production Planning (PP) & $\mathbf{X}$ & $X$ & $X$ & \\
\hline Quality Management (QM) & $X$ & & & \\
\hline Plant Maintenance (PM) & & & $X$ & \\
\hline Human Resources (HR) & $\mathbf{X}$ & & & \\
\hline Financial Accounting (FI) & $\mathbf{X}$ & $\mathbf{X}$ & $\mathbf{X}$ & $\mathbf{X}$ \\
\hline Controlling (CO) & $\mathbf{X}$ & $\mathbf{X}$ & $X$ & $\mathbf{X}$ \\
\hline Fixed Asset Mgmt. (AM) & & & & $\mathbf{X}$ \\
\hline
\end{tabular}

Figure 3 Application Modules and Processes

\section{Business Suites in SAP NetWeaver}

SAP NetWeaver consists of Supply-chain management (SCM), Customer Relationship Management (CRM), Supplier Relationship Management (SRM) and Project Product lifecycle management (PLM) business suites which are built on object data and BPPs as SAP NetWeaver sub-systems. Figure 4 illustrates the Internet enabled SAP Net-weaver System.

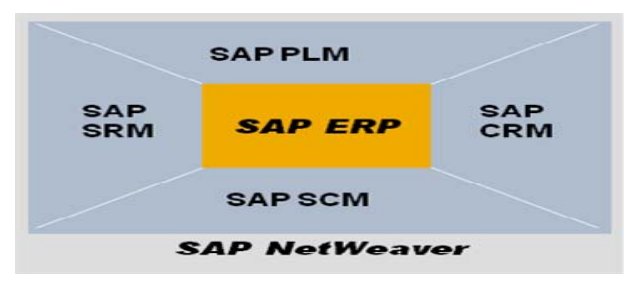

Figure 4 SAP Business Suites

\section{BUSINESS INTELLEGENCE DATA REUSE}

SAP business warehouse (BW) provides users with powerful analytical capabilities known as business intelligence that collect and analyze operational data from a variety of sources for decision making. SAP BW is a separate system that receives data from the SAP system. Unlike the OLAP database environment in SAP, SAP BW is not a real time system. Data in SAP BW reports are not tied to SAP real-time transactions and can be imported from SAP databases, other external flat data files, relational databases, multi-dimensional sources, XML data files or legacy applications as shown in Figure 5. 
Volume XII, No. 1, pp. 392-400, 2011

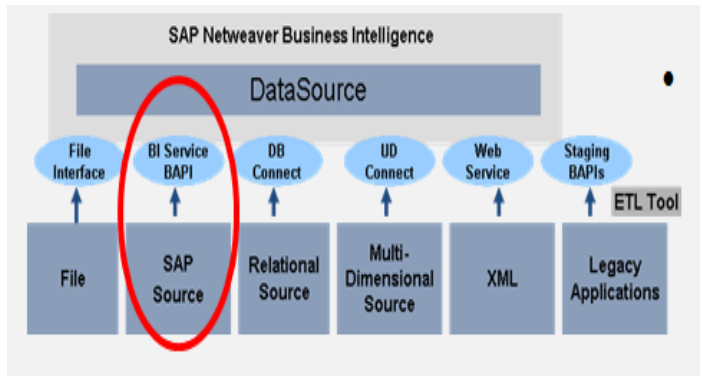

Figure 5 SAP BW Data Source

SAP business warehouses provide users with the opportunities to work with historical data to identify trends and pattern and provide business solutions to decision makers in the organization. Whereas ERP systems work with the current operational data in the enterprise databases, ERP data warehouse collect content from the various operational databases. Data warehouse data can be exported from the databases. ERP provides two report options: online transaction processing (OLTP) and analytical analysis processing (OLAP). OLTP generate reports in the form of lists: work lists and online lists based on the transaction data. OLAP generates detailed report using dedicated analytical tools based on aggregated data in information structure. Figure 6 illustrates how OLTP data are reused for OLAP. Figure 7 shows how SAP BW system collects objects required to activate an InfoCube.

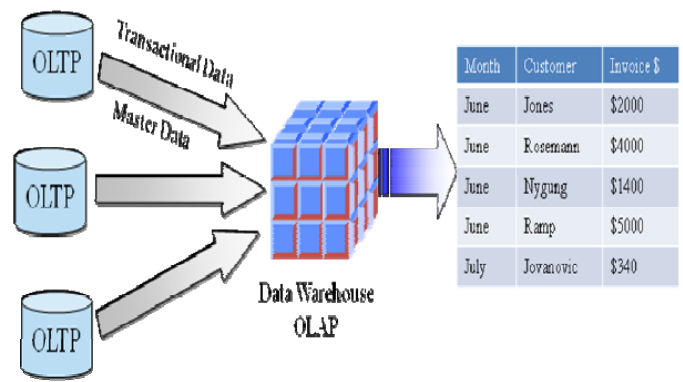

Figure 6 Data from databases to data warehouse

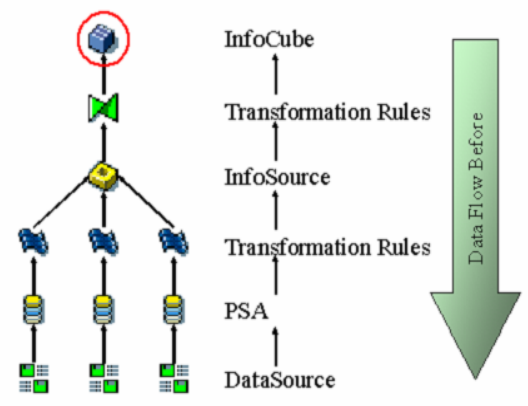

Figure 7 Data transformed into a data warehouse 
Volume XII, No. 1, pp. 392-400, 2011

\section{CASE STUDY: GLOBAL BIKE}

In 2001 Heidelberg Composite in Germany and Frankenstein Bikes in U.S. were merged to form Global Bike Incorporated (GBI). During 2009, GBI integrated a shared services model for all IT functions, implemented SAP ERP version 6.0 and became a process-centric organization. The centralized process offers GBI an integrated business platform that enables consistency of operations and process integrity across the globalized company in a higher controlled environment. Figure 3 illustrates the GBI organization chart with organizational data. The organizational diagram represents the organizational structure implemented within the SAP System. The organizational data are the company code being implemented for GBI. A client is an enterprise that is the highest organizational level in ERP. The enterprise consists of many companies. A plant can be a factory, warehouse or service center.

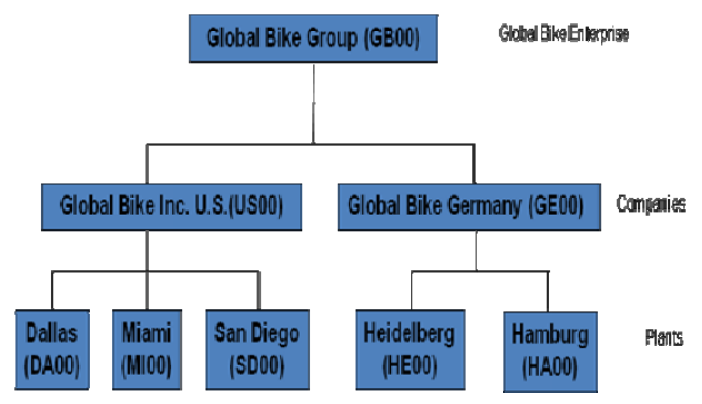

Figure 8 GBI Organizational Data

GBI instance sales data are stored in the centralized SAP database system for OLTP processing as shown in Figure 9.

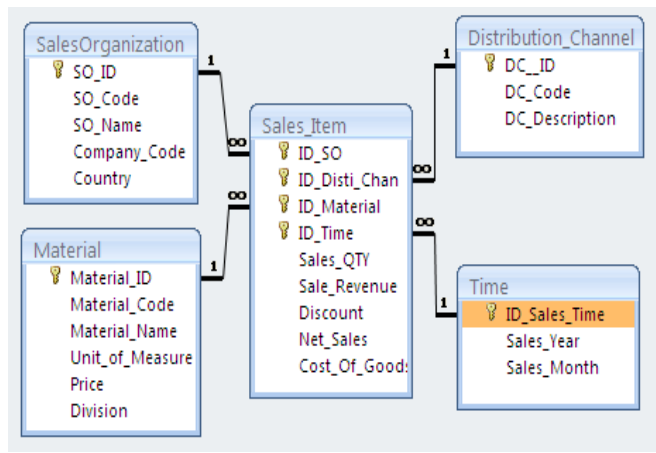

Figure 9 Sales Relational Database Schema

GBI historical data stored in the SAP Business data warehouse (BW) are extracted from the centralized SAP database system for OLAP processing as shown in Figure 10. 
Volume XII, No. 1, pp. 392-400, 2011

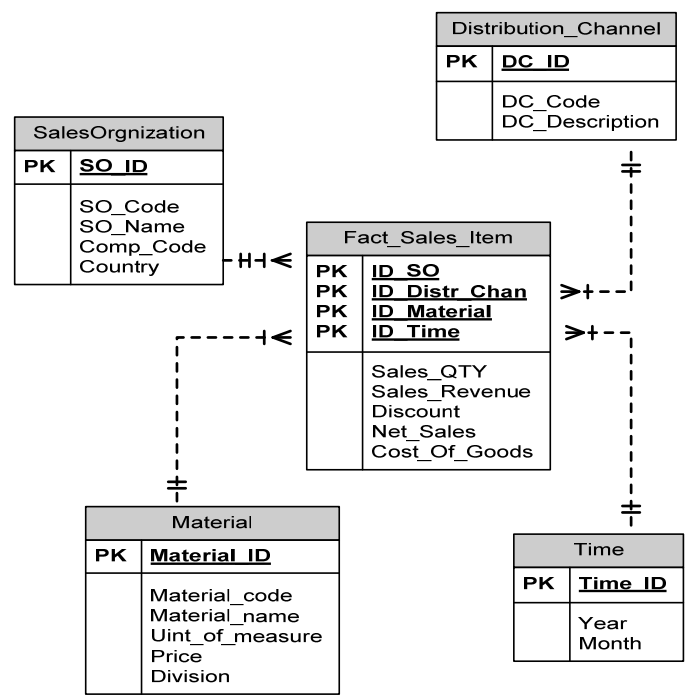

Figure 10 Sales Data Warehouse Star Schema

\section{ERP MASTER DATA INTEGRATION}

This section specifies enterprise data modeling and shows the overall picture of the organization data across many different departments in the enterprise. Enterprise modeling is to ensure that all applications that use integrated master data in ERP. Master data management (MDM) in ERP ensures the currency, meaning and quality of integrated data within and across various subject are. MDM does not address transactional data such as invoice and shipping notice. Master data have become important because they need to meet regulations such as the Sarbanes-Oxley Act. Master data cannot be deleted, but only moved to archives on ERP systems. Data in ERP can be classified into four categories.

- Organizational data are used to represent the structure of an enterprise include Client, company and plant data.

- Master data represent entities associated with the business processes such as buying materials from vendors and selling materials to customers. Master data are referenced more frequently than others across ERP systems in both operational systems and analytical systems.

- Situational data are specific to where and when the task being executed.

- Transaction data are combination of organizational data, master data and situational data. Transaction data reflect the consequences of process execution. Transaction data include dates, quantities, prices payment and delivery terms.

Transaction documents record transaction data during the transaction as the process is being executed. Transaction documents are purchase orders for vendors, packing lists for shipping and invoices as request for customers for payment of materials shipped. Post transaction documents record data after the process is finished. Post transaction documents include financial account (FI) document, controlling (CO) document and material documents. FI and CO documents record the financial impact of process steps. Account receivable documents are created after the company receives the payment from the customer. Materials documents record material movement from a vendor to a customer. Figure 11 shows relationship between transaction data, and organizational data, master data and situational data as well as transaction documents and post transaction documents. 
Volume XII, No. 1, pp. 392-400, 2011

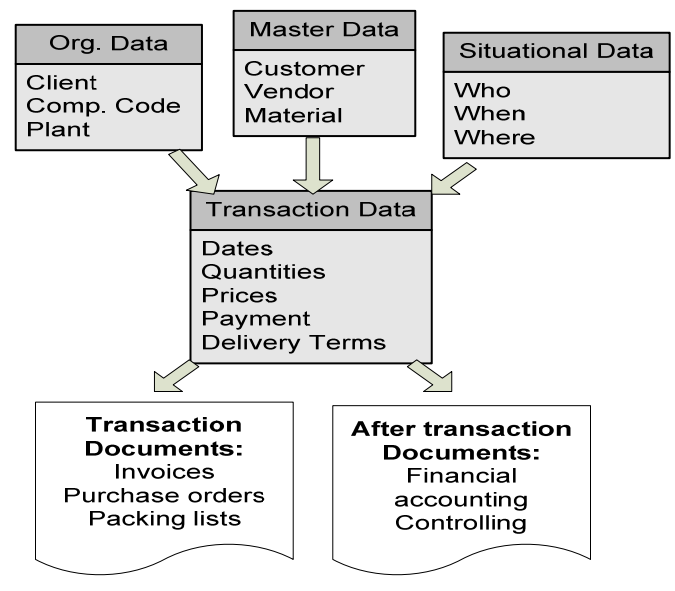

Figure 11 ERP Composition of Data [6]

The Business Function to Master Data Entity Matrix can be used for bottom-up approaches during customization of ERP to the organization business processes. In ERP data modeling, more bottom-up approaches are used for re-engineering or immigrating data from existing systems. Figure 12 shows how master data occur in major business functions in the value chain.

\begin{tabular}{|l|l|l|l|}
\hline & $\begin{array}{l}\text { Customer } \\
\text { data }\end{array}$ & $\begin{array}{l}\text { Vendor } \\
\text { data }\end{array}$ & $\begin{array}{l}\text { Material } \\
\text { data }\end{array}$ \\
\hline $\begin{array}{l}\text { Production } \\
\text { Planning }\end{array}$ & & $\mathrm{x}$ & $\mathrm{x}$ \\
\hline $\begin{array}{l}\text { Materials } \\
\text { Management }\end{array}$ & & $\mathrm{x}$ & $\mathrm{x}$ \\
\hline $\begin{array}{l}\text { Production } \\
\text { Operation }\end{array}$ & & $\mathrm{x}$ & $\mathrm{x}$ \\
\hline $\begin{array}{l}\text { Warehouse } \\
\text { Management }\end{array}$ & $\mathrm{x}$ & $\mathrm{x}$ & $\mathrm{x}$ \\
\hline $\begin{array}{l}\text { Sales } \\
\text { \&Marketing }\end{array}$ & $\mathrm{x}$ & $\mathrm{x}$ \\
\hline $\begin{array}{l}\text { Sales Order } \\
\text { Fulfillment }\end{array}$ & $\mathrm{x}$ & & $\mathrm{x}$ \\
\hline
\end{tabular}

Figure 12 Business Functions to Master Data Entity Matrix

The GBI database stores master data and updates the database instances. The three sets of master data most commonly used in an organization are customer master data, vendor master data and material master data [6]. Figure 13 illustrates GBI customer master data that are used in the fulfillment process. Figure 14 illustrates GBI Vendor data that are used in the procurement process. Figure 15 illustrates GBI material master data that are planned, purchased, sold and produced and are also used in service and maintenance. 
Volume XII, No. 1, pp. 392-400, 2011

\begin{tabular}{|lllrr}
\hline 10014 & NEWYORKCITY & BIG APPLE BIKES & 2000 & US00 \\
18033 & BOSTON & BEANTOWN BIKES & 5000 & US00 \\
19073 & PHILADELPHIA & PHILLY BIKES & 3000 & US00 \\
04227 & LEIPZIG & DRAHTESEL & 18000 & DE00 \\
16341 & BERLIN & CAPITAL EIKES & 16000 & DE00 \\
17389 & ANKLAM & OSTSEERAD & 21000 & DE00 \\
\hline
\end{tabular}

Figure 13 US \& German Customer Master Data

\begin{tabular}{|c|c|c|c|}
\hline ATLANTA & 000 & OLYMPIC PROTECTIVE GEAR & 101000 US00 \\
\hline CARLSBAD & 000 & REDWOOD KITS & 112000 US00 \\
\hline CINCINNATI & กกก & AOOMTOWN TIRF R WHFFI & 1กวกกก IJAกก \\
\hline AUGSBURG & 000 & LOHSE SCHRAUBE & $118000 \mathrm{DE} 00$ \\
\hline BIELEFELD & 000 & PYRAMID BIKING & $114000 \mathrm{DE} 00$ \\
\hline \multicolumn{2}{|c|}{ BRAUNSCHWEIG 000} & BURGMEISTER ZUBEHÖR OHG & $113000 \mathrm{DE} 00$ \\
\hline
\end{tabular}

Figure 14 US \& German Vendor Master Data

Raw material

\begin{tabular}{lll}
\hline BRAKE KIT & EN & BRKT1000 \\
CARBON COMPOSIT WHEEL & EN & CCWH1000 \\
CHAIN & EN & CHAN1000 \\
DERAILLEUR GEAR ASSEMBLY EN & DGAM1000
\end{tabular}

Semi-finished goods

CARBON COMPOSIT WHEEL ASSEMELY EN CCWA1000

OFF ROAD ALUMINUM WHEEL ASSEMELY EN ALWA1000

TOURING ALUMINUM WHEEL ASSEMELY EN ALWA2000

Finished goods

\begin{tabular}{lll}
\hline DELUXE TOURING BIKE (BLACK) & EN & DXTR1000 \\
\hline DELUXE TOURING BIKE (RED) & EN & DXTR3000 \\
DELUXE TOURING BIKE (SILVER) & EN & DXTR2000 \\
MEN'S OFF ROAD BIKE & EN & ORMN1000
\end{tabular}

Trading goods

\begin{tabular}{lll}
\hline AIR PUMP & EN & PUMP1000 \\
ELBOW PADS & EN & EPAD1000 \\
FIRST AID KIT & EN & FAID1000
\end{tabular}

Figure 15 Four Types of Material Master Data

\section{SUMMARY}

In summary, object data, business process procedures (BPPs) and application modules are predefined in ERP. They can be reused and integrated in the ERP system at different levels. Customizing data are built upon the predefined object data. Transactional data are built on the top of both object data and customizing data. Master data can be automatically propagated to and reused in all applications in ERP systems. In addition, all the data in ERP databases can also be reused and integrated in data warehouses for business intelligence reports.

The contribution of this paper is to identify and present the pattern of data reuse and integration features of ERP in the real world scenario. The significance of the paper is to provide ERP researchers, industrial practitioners and academia the guidelines on how object data are reused and integrated ERP systems. Object data reuse and integration provide standard data structure, data portability, security and maintainability in ERP systems. With object reuse and integration, standard adherence access path, ERP has a de facto standard for objects and multiple business applications. 


\section{Issues in Information Systems}

Volume XII, No. 1, pp. 392-400, 2011

\section{ACKNOWLEDGEMENTS}

The author would like to thank Professors Roger Hayen; Simha Magal and Jeffrey Word; and Ellen Monk and Bret Wagner for their books and informative insights. The author is also grateful to the SAP University Alliance Program for providing SAP software, server hosting and Global bike Incorporation case study.

\section{REFERENCES}

1. Anderson, G. W., Nilson, C. D. and Rhodes, T. (2009). SAP Implementation, Unleashed: a business and technical roadmap to deploying SAP, Sams.

2. Davis, C. and Comeau, J. (2004). Enterprise Integration in Business Education: Design and Outcomes of a Capstone ERP-based Undergraduate e-Business Management Course, Journal of Information Systems Education, 15(3), 287-99.

3. Guha, S.; Kettinger, W. J. and Teng, T. C. (1993). Business Process Reengineering: Building a Comprehensive Methodology, Information Systems Management.

4. Hayen, R. SAP R/3 Enterprise Software: an Introduction, McGraw-Hill, 2007

5. Holsing, D. D., (2007). Integration of specialized disciplines in business school curriculum: Applying the SAP process, University of South Dakota, 184 pages.

6. Magal, S.and Word, J. (2011). Integrated business Processes with ERP Systems, Wiley.

7. Monk, E. and Wagner, B. (2008). Concepts in Enterprise Resource Planning, Third Edition, Course Technology. 